\title{
Origin, differentiation and functional ultrastructure of egg envelopes in the cestode Echinococcus multilocularis Leuckart, 1863 (Cyclophyllidea: Taeniidae)
}

\author{
Zdzislaw Świderski $^{1}$ - Jordi Miquel ${ }^{2,3}$ - Samira Azzouz-Maache ${ }^{4}$. \\ Anne-Françoise Pétavy ${ }^{4}$
}

Received: 27 February 2017 / Accepted: 2 May 2017 /Published online: 7 June 2017

(C) The Author(s) 2017. This article is an open access publication

\begin{abstract}
The origin, differentiation and functional ultrastructure of oncospheral or egg envelopes in Echinococcus multilocularis Leuckart, 1863 were studied by transmission electron microscopy (TEM) and cytochemistry. The purpose of our study is to describe the formation of the four primary embryonic envelopes, namely vitelline capsule, outer envelope, inner envelope and oncospheral membrane, and their transformation into the oncospheral or egg envelopes surrounding the mature hexacanth. This transformation takes place in the preoncospheral phase of embryonic development. The vitelline capsule and oncospheral membrane are thin membranes, while the outer and inner envelopes are thick cytoplasmic layers formed by two specific types of blastomeres: the outer envelope by cytoplasmic fusion of two
\end{abstract}

This paper is dedicated to the memory of the distinguished German zoologist and parasitologist Professor Rudolph Leuckart (1822-1898), the author who described the examined here cestode species and who concluded discussion on the important role of Mehlis' gland, ootype and the vitelline granules of vitellocytes in the capsule formation. This dedication is made on the occasion of the approaching 120th anniversary of Professor R. Leuckart's death.

Zdzisław Świderski

z.swider@twarda.pan.pl

1 Witold Stefański Institute of Parasitology, Polish Academy of Sciences, 51/55 Twarda Street, 00-818 Warszawa, Poland

2 Secció de Parasitologia, Departament de Biologia, Sanitat i Medi Ambient, Facultat de Farmàcia i Ciències de l'Alimentació, Universitat de Barcelona, Av. Joan XXIII, sn, 08028 Barcelona, Spain

3 Institut de Recerca de la Biodiversitat (IRBio), Facultat de Biologia, Universitat de Barcelona, Av. Diagonal, 645, 08028 Barcelona, Spain

4 Laboratoire de Parasitologie et Mycologie Médicale, Faculté de Pharmacie, Université Claude Bernard-Lyon 1, 8 Av. Rockefeller, 69373 Lyon, Cedex 08, France macromeres and the inner envelope by cytoplasmic fusion of three mesomeres. Both outer and inner envelopes are therefore cellular in origin and syncytial in nature. During the advanced phase of embryonic development, the outer and inner envelopes undergo great modifications. The outer envelope remains as a metabolically active layer involved in the storage of glycogen and lipids for the final stages of egg development and survival. The inner envelope is the most important protective layer because of its thick layer of embryophoric blocks that assures oncospheral protection and survival. This embryophore is the principal layer of mature eggs, affording physical and physiological protection for the differentiated embryo or oncosphere, since the outer envelope is stripped from the egg before it is liberated. The embryophore is very thick and impermeable, consisting of polygonal blocks of an inert keratin-like protein held together by a cementing substance. The embryophore therefore assures extreme resistance of eggs, enabling them to withstand a wide range of environmental temperatures and physicochemical conditions.

Keywords Echinococcus multilocularis · Cestoda ·

Taeniidae $\cdot$ Egg envelopes $\cdot$ Envelopes origin and differentiation $\cdot$ Functional ultrastructure

\section{Introduction}

In the family Taeniidae, the genus Echinococcus includes species of great medical and veterinary importance, causing the important zoonotic infections cystic and alveolar echinococcosis. Echinococcus multilocularis is the zoonotic agent of human alveolar echinococcosis or alveolar hydatid disease. Its indirect life cycle includes wild canids and also dogs as definitive hosts harbouring the adult tapeworm, whereas some micromammals act as intermediate hosts harbouring the larval 
stage. Human infections with the metacestode of E. multilocularis result in alveolar hydatid disease which is still very common in different countries.

Formation of embryonic envelopes and their transformation into oncospheral or egg envelopes, as well as their number and terminology, are the most confusing topics of cestode embryogenesis (Rybicka 1965, 1966; Sakamoto 1981; Świderski 2008). Comparative study has been very difficult largely because of the lack of uniform terminology used by various authors. As early as 1966, Rybicka was trying to review and compare different terms used by various authors for the same oncospheral and egg envelopes (see Table 1 of Rybicka 1966). However, very recently, the problem of standardised terminology of embryonic envelopes of tapeworm was reviewed and updated by Conn and Świderski (2008) and is used in the present study.

The oncospheral or egg envelopes play an important role in protection, nutrition and metabolism of the infective oncospheres of cestodes (Rybicka 1965, 1966; Świderski 1983, 1988, 2008). They exhibit a large variety of modes of differentiation and their ultrastructure as related to the wide range of different cestode life cycles and their adaptations to different hosts and environmental conditions (Pence 1967, 1970; Nieland 1968; Świderski 1968, 1972, 1975, 1981, 2008; Świderski and Eckert 1977; Fairweather and Threadgold 1981; Conn 1988, 2000; Chomicz et al. 1995; Tkach and Świderski 1997, 1998; Świderski et al. 2000, 2001; Chomicz and Świderski 2004; Młocicki et al. 2005).

The scarcity of ultrastructural data on taeniid eggs may be partly explained by several serious disadvantages they present for electron microscope examination: a very thick, dense, rigid and impermeable embryophore composed of a thick layer of keratin-like protein blocks. These technical difficulties have impeded getting taeniid eggs properly fixed and infiltrated with embedding media to allow for cutting of the thick layer of keratinised embryophores (Świderski 1982, 1983, 1988, 1994) and dense, keratinised oncospheral hooks (Świderski et al. 2016a).

The purpose of the present study is to describe the origin, differentiation and functional ultrastructure of the oncospheral envelopes surrounding the eggs of Echinococcus multilocularis and to compare the results with published data on taeniids and other cyclophyllideans. However, the so-called hook region membrane that covers only one pole of the mature oncosphere and is directly attached to the oncosphere surface will be subject of a separated publication.

\section{Materials and methods}

\section{Materials}

Live specimens of E. multilocularis were isolated from the intestine of a naturally infected red fox (Vulpes vulpes L.) from La Roche sur Foron (France) captured in June 2014.

\section{TEM preparation of samples}

Adult tapeworms were immediately rinsed with a $0.9 \% \mathrm{NaCl}$ solution. Later, they were fixed in cold $\left(4{ }^{\circ} \mathrm{C}\right) 2.5 \%$ glutaraldehyde in a $0.1 \mathrm{M}$ sodium cacodylate buffer at $\mathrm{pH} 7.4$ for a minimum of $2 \mathrm{~h}$, rinsed in $0.1 \mathrm{M}$ sodium cacodylate buffer at $\mathrm{pH} 7.4$, post-fixed in cold $\left(4^{\circ} \mathrm{C}\right) 1 \%$ osmium tetroxide with $0.9 \%$ potassium ferricyanide in the same buffer for $1 \mathrm{~h}$, rinsed in Milli-Q water (Millipore Gradient A10), dehydrated in an ethanol series and propylene oxide, embedded in Spurr's resin and polymerised at $60^{\circ} \mathrm{C}$ for $72 \mathrm{~h}$.

Egg development was followed by selecting proglottids in different stages of maturation. Ultrathin sections $(60-90 \mathrm{~nm}$ thick) of these mature and gravid proglottids at different levels were obtained with a Reichert-Jung Ultracut E ultramicrotome. Sections were placed on $200-\mu \mathrm{m}$ mesh copper grids and double-stained with uranyl acetate and lead citrate according to the Reynolds (1963) methodology. The grids were examined in a JEOL 1010 transmission electron microscope (Jeol, Japan) operated at $80 \mathrm{kV}$, in the "Centres Científics i Tecnològics" of the University of Barcelona (CCiTUB).

\section{Freeze substitution and infiltration with Lowicryl resin}

Some specimens were fixed in cold $\left(4{ }^{\circ} \mathrm{C}\right) 4 \%$ paraformaldehyde $+0.1 \%$ glutaraldehyde in a $0.1 \mathrm{M}$ sodium cacodylate buffer at $\mathrm{pH} 7.4$ for a 4 to $5 \mathrm{~h}$ and then conserved in cold $\left(4{ }^{\circ} \mathrm{C}\right) 2 \%$ paraformaldehyde in the same buffer. Samples were rinsed in a $0.15 \mathrm{M}$ glycine in a $0.1 \mathrm{M}$ sodium cacodylate buffer at $\mathrm{pH} 7.4$, cryoprotected by crescent concentrations $(10,20$ and $30 \%$ ) of glycerol in the same buffer and then cryofixed in liquid propane.

Samples were freeze-substituted for 3 days at $-90{ }^{\circ} \mathrm{C}$ in anhydrous acetone containing $0.5 \%$ uranyl acetate. Then, they were warmed up to $-50{ }^{\circ} \mathrm{C}$, at $5{ }^{\circ} \mathrm{C} / \mathrm{h}$ (EM AFS2, Leica, Vienna, Austria). After several acetone rinses, samples were infiltrated with Lowicryl HM20 resin during 4 days. Samples were polymerised under UV light at $-50{ }^{\circ} \mathrm{C}$ for $24 \mathrm{~h}$, during the warming up at a rate $5{ }^{\circ} \mathrm{C} / \mathrm{h}$ until $22^{\circ} \mathrm{C}$ and $48 \mathrm{~h}$ at $22^{\circ} \mathrm{C}$.

Ultrathin sections were picked up on Formvar-coated nickel grids, double-stained with uranyl acetate and lead citrate and examined in a JEOL 1010 TEM operated at $80 \mathrm{kV}$, in the CCiTUB.

\section{Cytochemistry}

The periodic acid-thiocarbohydrazide-silver proteinate (PATCH-SP) technique of Thiéry (1967) was applied to determine the cytochemical localisation of glycogen at the ultrastructural level. Thus, ultrathin sections collected on gold grids were treated as follows: $30 \mathrm{~min}$ in $10 \% \mathrm{PA}$, rinsed in Milli-Q water; $24 \mathrm{~h}$ in TCH, rinsed in acetic solutions and 
Fig. 1 The early stages of embryonic development in Echinococcus multilocularis. a Fertilised oocyte or ovum and adjacent vitellocyte both surrounded by a newly formed vitelline capsule. Note capsule labyrinth membrane complex on the upper surface of the newly formed vitelline capsule and numerous $\beta$-glycogen granules in the cytoplasm of vitellocyte. $\mathbf{b}$ Part of an early embryo composed of oocyte, remnants of the vitelline cell with $\beta$-glycogen particles and two polar bodies. Note infolded labyrinth of capsular membrane in the left lower corner of the micrograph. $\beta$ - $g l \beta$-glycogen, $C$ vitelline capsule, $C L M$ capsule labyrinth membrane, $O v$ oocyte, $P B$ polar body, $V c$ vitellocyte
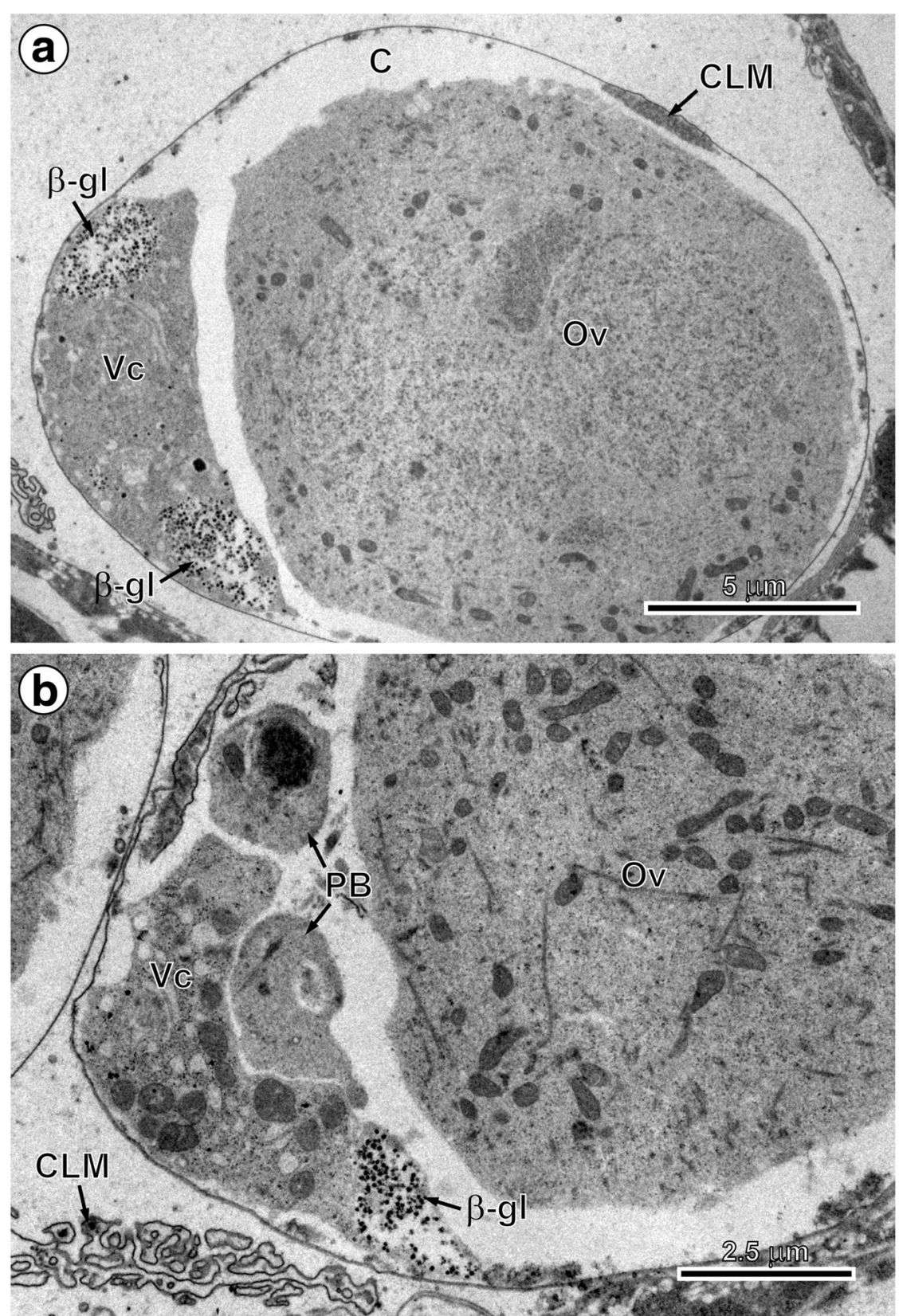

Milli-Q water; and 30 min in 1\% SP in the dark and rinsed in Milli-Q water. Gold grids were also examined in a JEOL 1010 TEM operated at an accelerating voltage of $80 \mathrm{kV}$, in the CCiTUB.

\section{Results}

\section{Origin and differentiation of egg envelopes}

The first embryonic envelope, the vitelline capsule, is a thin proteinaceous layer that forms from coalescence of material released by exocytosis from a single vitellocyte. This occurs after oocyte fertilisation and during passage of the fertilised ova and vitellocytes through the ootype that is surrounded by Mehlis' gland cells. It was observed at this stage that the vitelline material from the vitellocyte cytoplasm is transformed simultaneously into a labyrinth-like reservoir membrane which appears on the surface of the vitelline cell. The labyrinth unrolls, flattens and becomes smooth, with the exception of certain regions still remaining for a variable period in the labyrinthine state (Fig. 1a, b). It is referred to as a "labyrinth-like membrane" by Świderski et al. (1970) or capsule "reticular mass" by Conn (1988). The role of Mehlis' gland secretion on the release of vitelline material from the vitellocytes appears evident.

In the early and advanced preoncospheral phase of development of the taeniid cestode E. multilocularis, four primary 

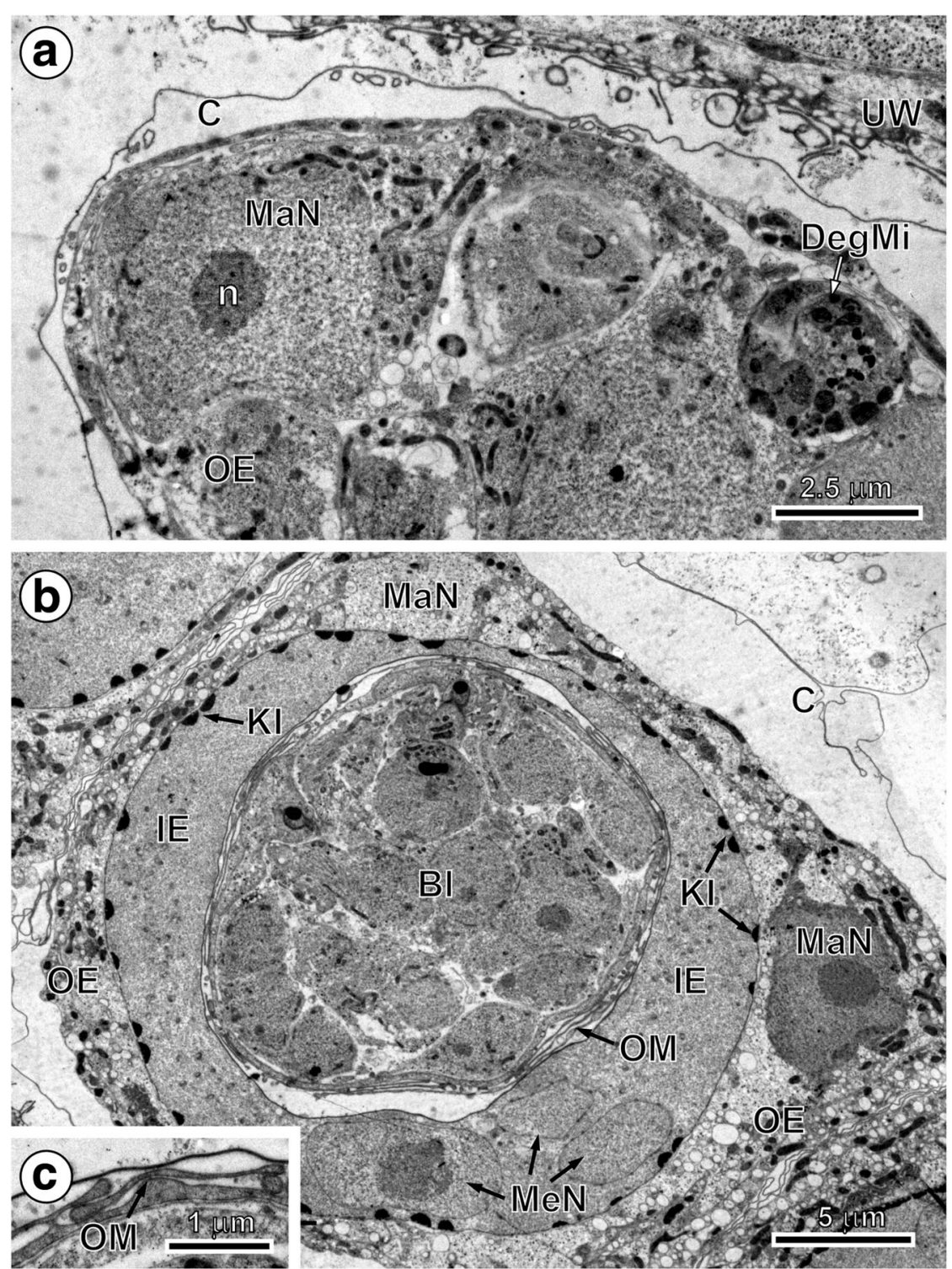

Fig. 2 Initial stages of the outer and inner envelope formation. a Part of an early embryo adjacent to uterine wall. Note (1) already formed membraneous vitelline capsule surrounding an early embryo composed of several blastomeres of different sizes and (2) a large macromere, situated under the vitelline capsule at the periphery of other blastomeres, which contains predominant nucleus with spherical electron-dense nucleolus, which takes part in the outer envelope formation. b Preoncospheral phase in more advanced stage of embryonic development. Four primary embryonic envelopes (vitelline capsule, outer envelope, inner envelope and oncospheral membrane) are clearly visible. In the outer envelope, note large nucleus of macromeres which predominant nucleolus, numerous elongated mitochondria and higher concentration of free ribosomes. In the inner envelope, note three nuclei of mesomeres, the fusion of which forms the cytoplasm of the syncytial layer. c Detail of the oncospheral membrane. $B l$ blastomere, $C$ vitelline capsule, DegMi degenerating micromere, $I E$ inner envelope, $K I$ keratin-like protein islands, $M a N$ macromere nucleus, $M e N$ mesomere nucleus, $n$ nucleolus, $O E$ outer envelope, $O M$ oncospheral membrane, $U W$ uterine wall embryonic envelopes are formed: vitelline capsule, outer envelope, inner envelope and oncospheral membrane (Figs. 2b, c, 3a, b and 4a, b). Two of them, the vitelline capsule and oncospheral membrane, are simply thin membranes (Figs. 2b, c, 3a and 4a, b), while the outer and inner envelopes are thick cytoplasmic layers formed by two specific types of blastomeres: the outer envelope is formed by cytoplasmic fusion of two macromeres and the inner envelope by a cytoplasmic fusion of three mesomeres (Figs. 2b, 3a, b and 4a, b). Both the outer and inner envelopes of E. multilocularis are therefore cellular in origin and syncytial in nature.

During advanced phase of embryonic development, the outer and inner envelopes undergo great modifications. The outer envelope remains for a long time as a metabolically active layer that is involved also in the storage of nutritive reserves in the form of glycogen and lipids for final stages of egg development and survival (Fig. 5). The inner envelope 
Fig. 3 Ultrastructure of embryos in advanced preoncospheral phase of development. a Part of an embryo surrounded by four embryonic envelopes, namely vitelline capsule, outer envelope, inner envelope with nucleus of mesomere and oncospheral membrane. b Part of an embryo composed of numerous

blastomeres. Note the initial stage of embryophoric block formation composed of small electron-dense islands of keratin-like protein situated under the outer membrane of the inner envelope which shows the nucleus of mesomere participating in its formation. $B l$ blastomere, $C$ vitelline capsule, $I E$ inner envelope, $K I$ keratin-like protein islands, $\mathrm{MeN}$ mesomere nucleus, $O E$ outer envelope, $O M$ oncospheral membrane
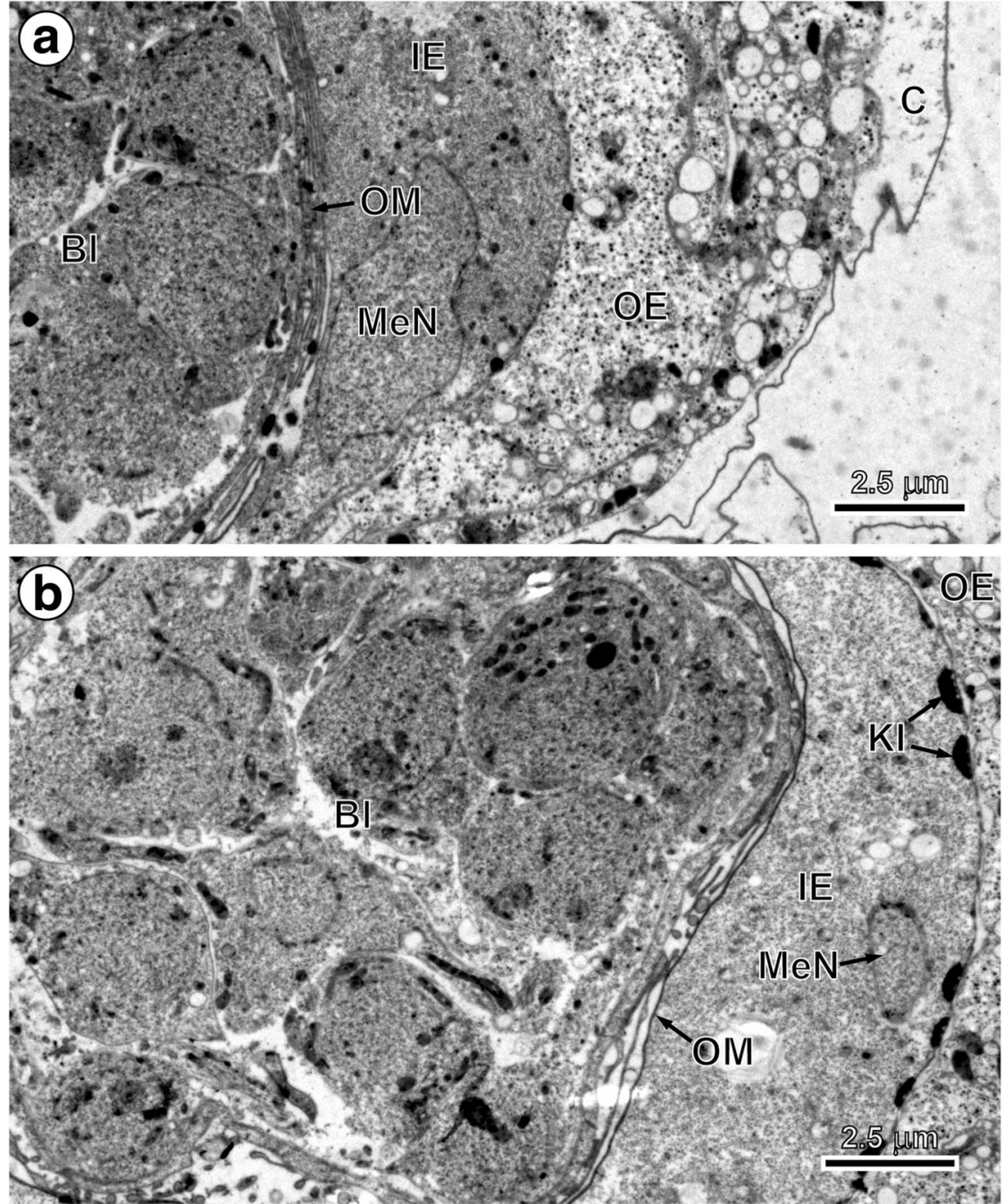

is the most important protective layer that, due to a thick layer of embryophoric blocks, assures oncospheral protection and survival (Fig. 5).

The delicate membranous vitelline capsule formed of the material originating from vitelline cells is initially infolded of a thin delicate membrane (Fig. 1a, b) but always remains visible in the intrauterine fully formed eggs at the outer surface of the outer envelope (Fig. 5).

The outer envelope is formed by a fusion of two large macromeres in the preoncospheral phase of the egg formation. At this stage, it is the thickest of all oncospheral envelopes (Figs. 2a, b, 3a and 4a). It consists of a thick layer of syncytial cytoplasm containing large nuclei of two macromeres with prominent electron-dense nucleoli (Figs. 2a, b and 4a). The cytoplasm of the outer envelope contains numerous elongated mitochondria, free ribosomes and polyribosomes randomly dispersed in all cytoplasm (Fig. 3a).

Within the primary inner envelope, two further layers differentiate progressively. They consist of (1) an outer sub-layer involved in embryophore formation (Figs. 2b, 3b and 4a, b) and (2) the inner syncytial sub-layer containing three mesomere nuclei in the early stages (Figs. 2b, 3a, b and 4b) which become very flat, and the entire sub-layer become transformed in granular layer of the inner envelope (Fig. 5).

The beginning of embryophoric block formation can be noted beneath the outer membrane of the inner envelope (Figs. 2b, 3b and 4a). The first keratin-like protein deposits were observed as flattened keratin-like protein islands forming discontinuous layer all around beneath the outer membrane of the inner envelope (Figs. 2b, 3b and 4a). They appear to increase in size by accretion and come to line the plasma membrane without fusing to one another (Figs. $4 \mathrm{~b}$ and 5).

The embryophore of E. multilocularis is thick and composed of numerous keratin-like protein blocks, giving it striated appearance in the sections (Fig. 5).

E. multilocularis eggs are spherical to ellipsoid in shape. In our specimens, mature eggs range in size from 33 to $39 \mu \mathrm{m}$ and from 26 to $33 \mu \mathrm{m}$ in their two diameters $(36 \times 30 \mu \mathrm{m}$, 
Fig. 4 Ultrastructure of Echinococcus multilocularis eggs in the middle and more advanced preoncospheral phase of the embryonic development. a

Median cross section through the entire egg in the middle phase of preoncospheral development. Note the (1) presence of four embryonic envelopes (vitelline capsule, outer envelope, inner envelope and oncospheral membrane), undergoing differentiation into oncospheral or egg envelopes, (2) presence of a large nucleus of macromere in the outer envelope, (3) presence of a discontinuous layer of flat embryophoric islands of keratin-like protein adjacent to the outer membrane of the inner envelope and (4) evident detachment of the oncospheral membrane from the inner surface of the inner envelope which participated in its formation. b Part of the embryo showing a thin layer of embryophoric blocks and two large flattened mesomere nuclei with prominent electron-dense nucleoli situated in the deeper granular sub-layer of the inner envelope. $B l$ blastomere, $C$ vitelline capsule, $E m B$ embryophoric blocks of keratin-like protein, $I E$ inner envelope, $K I$ keratin-like protein islands, $\mathrm{MaN}$ macromere nucleus, $M e N$ mesomere nucleus, $n$ nucleolus, $O E$ outer envelope, $O M$ oncospheral membrane, $U W$ uterine wall
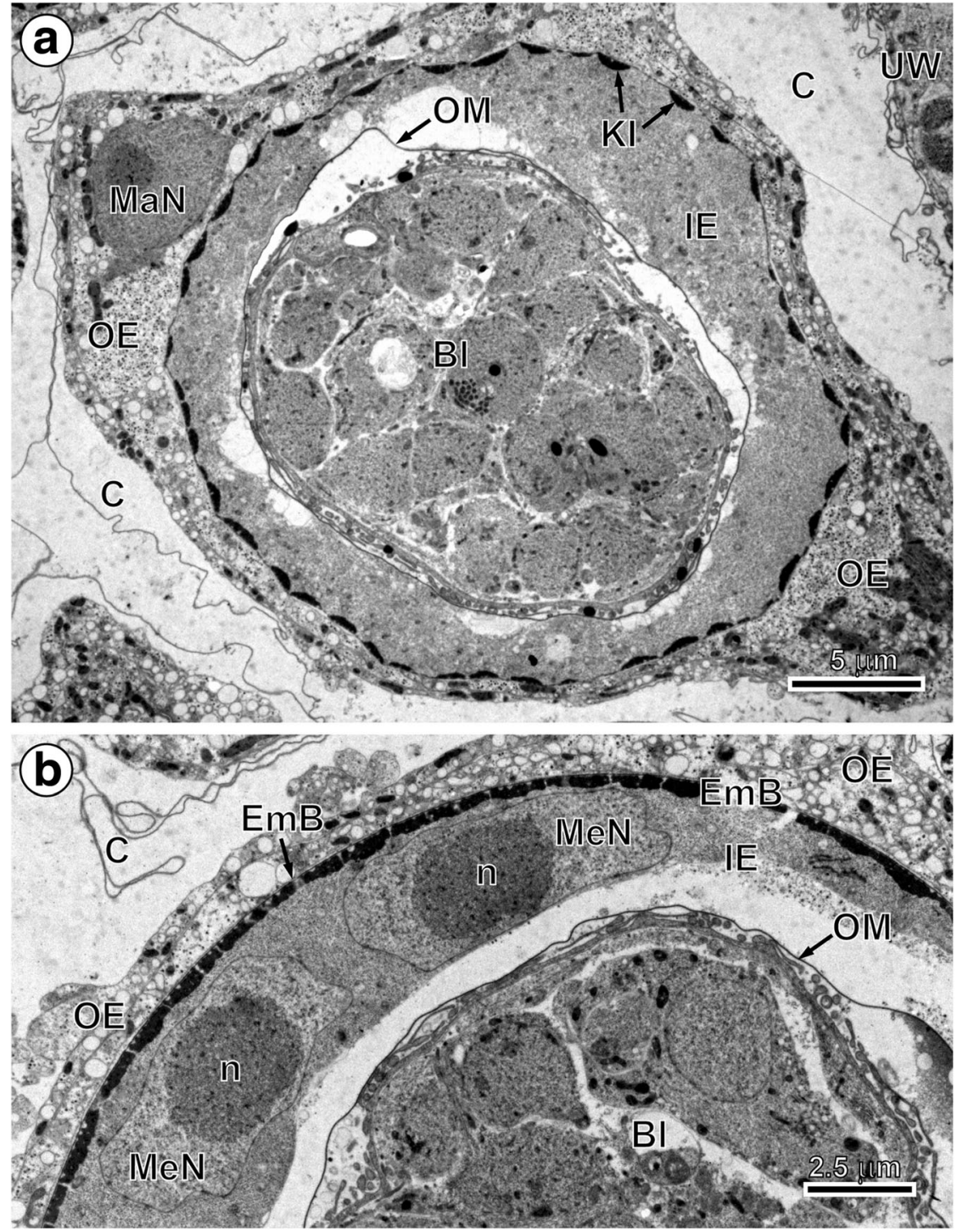

average of 15 eggs). The differentiating and mature eggs are surrounded by several layers of four primary envelopes which undergo differentiation into the secondary envelopes, the so-called oncospheral or egg envelopes (Fig. 6).

The embryophore is the principal layer of mature eggs affording physical and physiological protection to the differentiation embryo or oncosphere, since the outer envelope is stripped from the egg before it is liberated. The embryophore is very thick and impermeable, consisting of polygonal blocks composed of an inert keratin-like protein which are held together by a cementing substance. It assures the extreme resistance of eggs enabling them to withstand a wide range of environmental temperatures and physicochemical conditions.

\section{Functional ultrastructure of egg envelopes}

The main function of the vitelline capsule is protection of an early embryo by three types of blastomeres formed during cleavage divisions. At this stage, it contains a small amount of nutritive material in the form of $\beta$-glycogen from the degenerating vitellocyte and the uterine wall.

The outer envelope's function is mainly high metabolic activity from large numbers of mitochondria, ribosomes and polyribosomes and from two large nuclei of macromeres with prominent nucleoli. Storage of nutritive reserves in the form of $\beta$-glycogen and highly saturated osmiophobic lipid droplets also represents an important source of energy in the intrauterine eggs. Both the vitelline capsule and outer envelope are stripped from the eggs during their liberation into the external environment. 


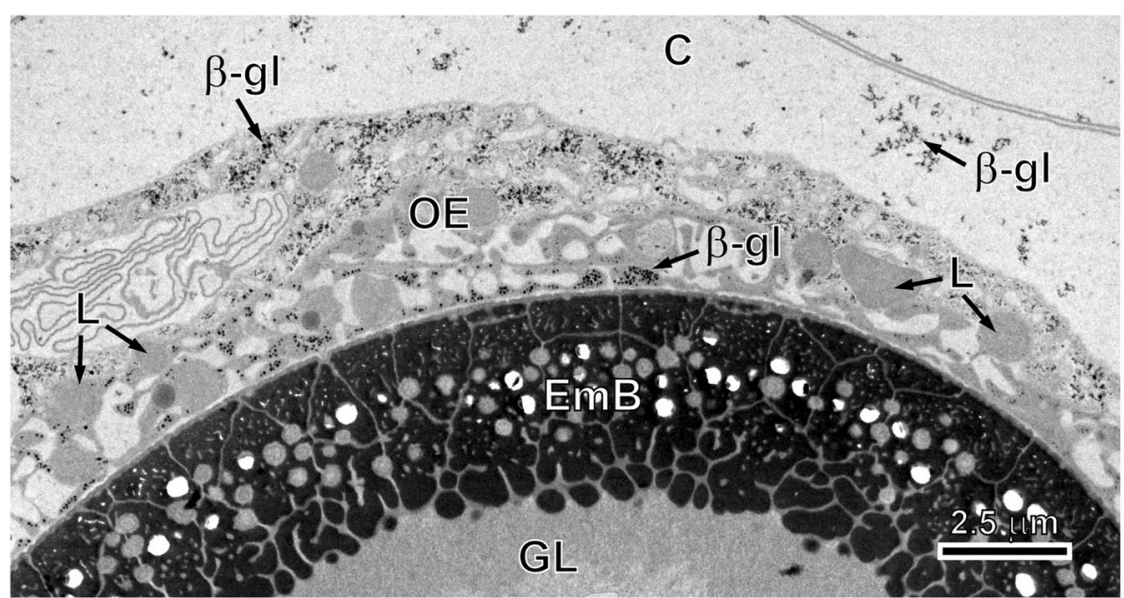

Fig. 5 Three external layers of egg envelopes after Thiéry cytochemical test for glycogen. Note (1) several $\beta$-glycogen particles and numerous unsaturated lipid droplets in the cytoplasm of the outer envelope, (2) very thick layer of embryophoric blocks in the outer part of the inner envelope with numerous vacuoles and the degenerating small mitochondria embedded between the embryophoric blocks and (3) part of the granular layer of the inner envelope situated under the embryophoric blocks. $\beta-g l$ $\beta$-glycogen, $C$ vitelline capsule, $E m B$ embryophoric blocks of keratinlike protein, $G L$ granular layer of embryophore, $L$ saturated, osmiophobic lipid droplets, $O E$ outer envelope
The inner envelope is the most important protective layer assuring remarkable impermeability and resistance of eggs to a wide range of environmental temperatures, dry climate and a great number of ovicidal substances. However, some impermeability may be due to enzymes that affect the cementing substance of the inert keratin-like protein blocks of the embryophore causing it to disintegrate into its component parts.

In addition to producing keratin-like protein blocks and cement substance, the inner envelope also takes part in the formation of the oncospheral membrane. This innermost membraneous envelope originates by delamination of the inner sub-layer of the inner envelope.

\section{Discussion}

In the study of egg development, the role of Mehlis' gland or vitellocytes in vitelline capsule or shell formation has been described and confirmed by numerous authors (Leuckart 1886; Smyth and Clegg 1959; Rybicka 1966; Mackiewicz 1968; Świderski et al. 1970). By comparison, our knowledge of egg envelope development and variation in diverse cestodes is less well known.

Over the past 50 years, many papers have been published on the ultrastructure and development of oncospheral envelopes from a wide diversity of cestode species. Indeed, even the more recent literature on cestode egg development and envelopes contains many variations in both the terminology and interpretations. Some of this variation may reflect honest differences of opinion and interpretation. On the other hand, other variations may reflect that cestodes are phylogenetically divers within their respective orders and families and have diverse ecological conditions/cycles that may indeed affect selection for different embryonic or egg envelope structure and that selection and adaptation may vary in different parts of the world.

During the last 50 years, there has been a rapidly growing literature on the ultrastructure of cestode embryonic and egg envelopes of cyclophyllidean cestodes, including taeniids (Pence 1967, 1970; Chew 1983; Conn 1985, 2000; Burt 1987; Conn and Kissel 1991; Świderski et al. 2000, 2001, 2016b; Młocicki et al. 2005; Jabbar et al. 2010a, 2010b). Yet, problems exist.

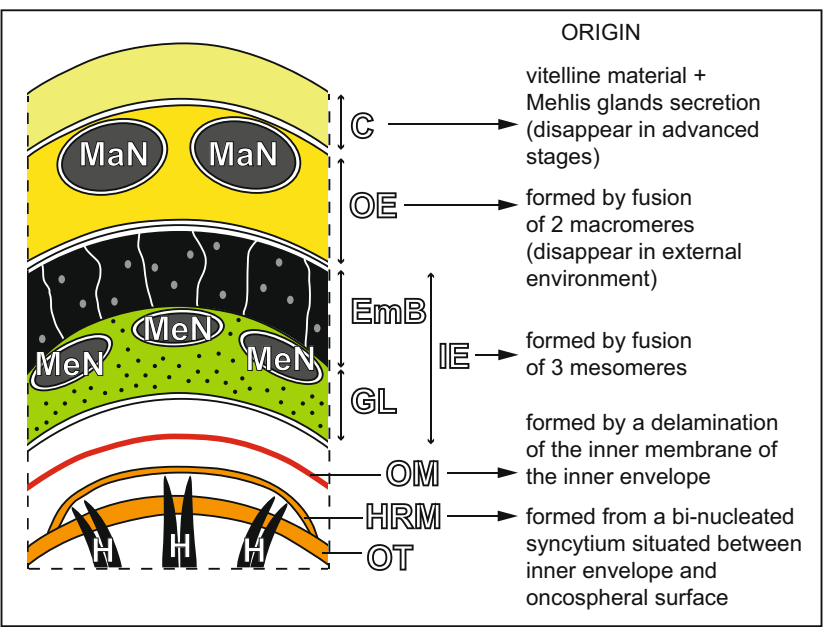

Fig. 6 Schematic diagram recapitulating our data on egg envelope ultrastructure with notes on the origin of different layers. $C$ vitelline capsule, $E m B$ embryophoric blocks of keratin-like protein, $G L$ granular layer of embryophore, $H$ oncospheral hooks, $H R M$ hook region membrane, $I E$ inner envelope, $M a N$ macromere nucleus, $M e N$ mesomere nucleus, $O E$ outer envelope, $O M$ oncospheral membrane, $O T$ oncospheral tegument 
As indicated by Rybicka (1965, 1966), much confusion and contradiction exist in the terminology used to describe light (LM) and electron microscopical (SEM and TEM) findings of embryonic envelopes of cyclophyllidean cestodes, including taeniids, of medical and veterinary importance. For example, Morseth (1965) reported that the egg envelopes of taeniids are made of eight distinct layers and membranes: (1) egg capsule, (2) vitelline layer, (3) outer embryophoric membrane, (4) embryophore, (5) granular layer, (6) basal membrane of granular layer, (7) oncospheral membrane and (8) limiting membrane. Though Sakamoto (1981) confirmed more or less the results obtained by Morseth (1965) on other taeniids. He wrote in an abstract, however, that the envelopes surrounding E. multilocularis oncospheres number up to six: (1) egg capsule, (2) vitelline layer, (3) outer embryophoric membrane, (4) embryophore, (5) granular layer and (6) oncospheral membrane.

Some misinterpretations in Morseth's paper (Morseth 1965) have been corrected. According to Nieland (1968), the "large cellular structures" in the granular layer of the inner envelopes, situated beneath the embryophore blocks described by Morseth (1965), "might represent the nucleus and nucleolus of this cell." In reality, the three nuclei situated in this layer certainly represent the nuclei of mesomeres, containing prominent nucleoli, which initially form this inner envelope by their cytoplasmic fusion. We conclude that the "circular bodies" of Morseth (1965) represent mitochondria which in the initial stage of embryophore formation seem to be the focal points for deposition of the block substance. They are certainly involved in the synthesis or maintenance of the integrity of the cement substance that is visible between the blocks. Morseth (1966) described the chemical composition of the blocks as resembling keratin, but the nature of the cement substance is unknown. According to Nieland (1968), some of the impermeability of the eggshell may be due to the cement substance and that the latter is probably the substrate for the enzymes which cause the embryophore to disintegrate into its component blocks. According to Nieland (1968), it is interesting to compare the single layer of blocks of the taeniid embryophores with the embryophore of Dipylidium caninum that is composed of two layer of rods at right angles to each other (Pence 1967).

In addition to producing the blocks and cement substance, the inner envelope of taeniid cestodes also appears to participate in the formation of the oncospheral membrane. Rybicka (1966) reported that the oncospheral membrane is formed by the delamination of the innermost part of the inner envelope.

E. multilocularis and other taeniid eggs show remarkable impermeability and resistance to the destructive action of ovicidal substances (Rarnell 1965; Mackie and Parnell 1967). Many years earlier, Skvortsov (1942) and Nosik (1952) recognised that the infectivity of taeniid eggs persisted in alcohol or in formalin for several hours. The very high resistance of taeniid eggs against ovicidal agents is certainly dependent upon the thick embryophore blocks of keratin-like protein held together by a cement substance. According to Sakamoto (1981), there is some hope that the impermeable outer embryophoric membrane (i.e. the outer membrane of the inner envelope) may be changed into a porous membrane by digestion of granules packed in the pores. He further concluded that his observations have been used in investigations on ovicidal substances against echinococcal eggs.

Better knowledge of the functional ultrastructure and cytochemistry of egg protecting envelopes in taeniid cestodes may contribute to discovering more effective ovicidal substances against extremely resistance parasite eggs that so far are resistant to tested drugs and physicochemical factors.

Acknowledgements This study was financially supported by the European Commission Contract KBBE 2010 1.3-01 265862 (PARAVAC). We wish to thank Professor John S. Mackiewicz, State University of New York at Albany, for his helpful suggestions, editing and commenting on an earlier version of the manuscript. The authors are grateful to Almudena García from the "Centres Científics i Tecnològics" of the University of Barcelona (CCiTUB) for her assistance in the preparation of samples. We are also grateful to François Contat from the "Clinique Vétérinaire des Afforêts" and the "Lieutenant de Louveterie" (La Roche sur Foron, France) for their help during fieldwork. JM is a member of the AGAUR group (2014 SGR 1241).

Open Access This article is distributed under the terms of the Creative Commons Attribution 4.0 International License (http:// creativecommons.org/licenses/by/4.0/), which permits unrestricted use, distribution, and reproduction in any medium, provided you give appropriate credit to the original author(s) and the source, provide a link to the Creative Commons license, and indicate if changes were made.

\section{References}

Burt MDB (1987) Early morphogenesis in the platyhelminthes with special reference to egg development and development of cestode larvae. Int J Parasitol 17:241-253. doi:10.1016/0020-7519(87)900476

Chew MWK (1983) Taenia crassiceps: ultrastructural observations on the oncosphere and associated structures. J Helminthol 57:101113. doi:10.1017/S0022149X00009354

Chomicz L, Świderski Z (2004) Functional ultrastructure of the oncospheral envelopes of twelve species of the family Hymenolepididae, Ariola, 1899, with aquatic life cycles. Acta Parasitol 49:177-181

Chomicz L, Świderski Z, Grytner-Ziêcina B (1995) Ultrastructure of the oncospheral envelopes and their differentiation in the cestode, Dicratotaenia coronula (Dujardin, 1845) (Cyclophyllidea, Hymenolepididae). Acta Parasitol 40:31-36

Conn DB (1985) Fine structure of the embryonic envelopes of Oochoristica anolis (Cestoda: Linstowiidae). Z Parasitenkd 71: 639-648. doi:10.1007/BF00925597

Conn DB (1988) Development of the embryonic envelopes of Mesocestoides lineatus (Cestoda: Cyclophyllidea). Int J Invert Reprod Dev 14:119-130 
Conn DB (2000) Atlas of invertebrate reproduction and development, 2nd edition. John Wiley \& Sons, Inc., New York

Conn DB, Kissel GE (1991) Ultrastructure of the embryonic envelopes of tapeworms of the genus Vampirolepis (Platyhelminthes: Cyclophyllidea: Hymenolepididae). Trans Am Microsc Soc 110: 86-87

Conn DB, Świderski Z (2008) A standardised terminology of the embryonic envelopes and associated developmental stages of tapeworms (Platyhelminthes: Cestoda). Folia Parasitol 55:42-52

Fairweather I, Threadgold LT (1981) Hymenolepis nana: the fine structure of the embryonic envelopes. Parasitology 82:429-443. doi:10. 1017/S0031182000066968

Jabbar A, Crawford S, Młocicki D, Świderski ZP, Conn DB, Jones MK, Beveridge I, Lightowlers MW (2010a) Ultrastructural reconstruction of Taenia ovis oncospheres from serial sections. Int J Parasitol 40:1419-1431. doi:10.1016/j.ijpara.2010.04.011

Jabbar A, Świderski Z, Młocicki D, Beveridge I, Lightowlers MW (2010b) The ultrastructure of taeniid cestode oncospheres and localization of host-protective antigens. Parasitology 137:521-535. doi: 10.1017/S0031182009991260

Leuckart R (1886) Die Parasiten des Menschen und die von ihnen herrührended Krankheiten, 2nd Edition. CF Winter'sche Verlagshandlung, Leipzig

Mackie A, Parnell IW (1967) Some observations on taeniid ovicides: the effects of some organic compounds and pesticides on activity and hatching. J Helminthol 41:167-210. doi:10.1017/ S0022149X00021581

Mackiewicz JS (1968) Vitellogenesis and egg-shell formation in Caryophyllaeus laticeps (Pallas) and Caryophylloides fennica (Schneider) (Cestoidea: Caryophyllidea). Z Parasitenkd 30:18-32. doi:10.1007/BF00329472

Młocicki D, Świderski Z, Eira C, Miquel J (2005) An ultrastructural study of embryonic envelope formation in the anoplocephalid cestode Mosgovoyia ctenoides (Railliet, 1890) Beveridge, 1978. Parasitol Res 95:243-251. doi:10.1007/s00436-004-1276-4

Morseth DJ (1965) Ultrastructure of developing taeniid embryophores and associated structures. Exp Parasitol 16:207-216. doi:10.1016/ 0014-4894(65)90045-7

Morseth DJ (1966) Chemical composition of embryophoric blocks of Taenia hydatigena, Taenia ovis and Taenia pisiformis eggs. Exp Parasitol 18:347-354. doi:10.1016/0014-4894(66)90037-3

Nieland ML (1968) Electron microscope observations on the egg of Taenia taeniaeformis. J Parasitol 54:957-969

Nosik AF (1952) Resistance of the oncospheres of Echinococcus granulosus to some physical and chemical factors. Trud khar'kov vet Inst 21:304-311

Pence DB (1967) The fine structure and histochemistry of the infective eggs of Dipylidium caninum. J Parasitol 53:1041-1054

Pence DB (1970) Electron microscope and histochemical studies of the eggs of Hymenolepis diminuta. J Parasitol 56:84-97

Rarnell IW (1965) Some observations on taeniid ovicides: screening techniques, and effects of some inorganic compounds. J Helminthol 39:257-272. doi:10.1017/S0022149X00020654

Reynolds ES (1963) The use of lead citrate at high $\mathrm{pH}$ as an electronopaque stain in electron microscopy. J Cell Biol 17:208-212

Rybicka K (1965) The embryonic envelopes in cyclophyllidean cestodes. Acta Parasitol Pol 13:25-34

Rybicka K (1966) Embryogenesis in cestodes. Adv Parasitol 4:107-186

Sakamoto T (1981) Electron microscopical observations on the egg of Echinococcus multilocularis. Mem Fac Agr Kagoshima Univ 17: 165-174

Skvortsov AA (1942) Egg structure on Taeniarhynchus saginatus and its control. Zool Zhur 21:10-18

Smyth JD, Clegg JA (1959) Egg-shell formation in trematodes and cestodes. Exp Parasitol 8:286-323. doi:10.1016/0014-4894(59)90027$\mathrm{X}$
Świderski Z (1968) Electron microscopy of embryonic envelope formation by the cestode Catenotaenia pusilla. Exp Parasitol 23:104-113. doi:10.1016/0014-4894(68)90048-9

Świderski Z (1972) La structure fine de l'oncosphère du cestode Catenotaenia pusilla (Goeze, 1782) (Cyclophyllidea, Catenotaeniidae). La Cellule 69:207-237

Świderski Z (1975) Comparative fine structure of cestode embryos. In: Proc 2nd EMOP, Trogir, pp 265-273

Świderski Z (1981) Reproductive and developmental biology of the cestodes. In: Clark WH Jr, Adams TS (eds) Advances in Invertebrate Reproduction. Elsevier/North Holland, New York

Świderski Z (1982) Echinococcus granulosus: embryonic envelope formation. In: Le Poole JB, Zeitler E (eds) Electron Microscopy 1982, Proc 10th Int Congr Electr Microsc, Hamburg 3, pp 513-514

Świderski Z (1983) Echinococcus granulosus: hook-muscle system and cellular organisation of infective oncospheres. Int J Parasitol 13: 289-299. doi:10.1016/0020-7519(83)90040-1

Świderski Z (1988) Comparative ultrastructure of taeniid eggs. In: Banchorndhevakul W, Ingkaninun P (eds) Mangclaviraj V. Proc IVth Asia-Pacific Conf \& Workshop Electr Microsc, Bangkok, pp 697-698

Świderski Z (1994) Ultrastructure of the infective oncospheres of Echinococcus multilocularis (Cyclophyllidea, Taeniidae). In: Jouffrey B, Colleix C (eds) Electron Microscopy 1994, Proc 13th Int Congr Electr Microsc, Paris, pp 1421-1422

Świderski Z (2008) Biodiversity of parasite eggs: their importance for disease dissemination and diagnostics. In: Commemorative Volume of Proceedings Published on the Occasion of the International Conference Dedicated to the 130th Anniversary of the Birthday of Academician K.I. Skrjabin, pp 453-459

Świderski Z, Eckert J (1977) Electron microscope and histochemical studies on the oncospheres of Echinococcus granulosus. Parasitology 75:xix-xxx

Świderski Z, Huggel H, Schönnenberger N (1970) The role of the vitelline cell in the capsule formation during embryogenesis in Hymenolepis diminuta (Cestoda). In: Proc 7th Int Congr Electr Microsc, Grenoble, pp 669-670

Świderski Z, Tkach VV, Vaucher C (2000) Fine structure of the infective eggs of the dilepidid cestode Hepatocestus hepaticus (Baer, 1932), a parasite of shrews. Acta Parasitol 45:71-82

Świderski Z, Ndiaye PI, Miquel J, Tkach V, Marchand B, Chomicz L, Sereda M (2001) Ultrastructural study of the embryonic development of the anoplocephalid cestode Anoplocephaloides dentata, an intestinal parasite of Arvicolidae rodents. I. Egg envelope formation. Acta Parasitol 46:171-185

Świderski Z, Miquel J, Azzouz-Maache S, Pétavy A-F (2016a) Echinococcus multilocularis (Cestoda, Cyclophyllidea, Taeniidae): oncospheral hook morphogenesis. Parasitol Res 115:3715-3721. doi:10.1007/s00436-016-5131-1

Świderski Z, Miquel J, Conn DB (2016b) Functional ultrastructure of eggs and cellular organization of hexacanths of the cyclophyllidean cestode Thysanotaenia congolensis: a phylogenetic implication of obtained results. Parasitology 143:320-333. doi:10.1017/ S0031182015001560

Thiéry JP (1967) Mise en évidence des polysaccharides sur coupes fines en microscopie électronique. J Microsc 6:987-1018

Tkach VV, Świderski Z (1997) Late stages of egg maturation in the cestode Pseudhymenolepis redonica Joyeux et Baer, 1935 (Cyclophyllidea, Hymenolepididae), a parasite of shrews. Acta Parasitol 42:97-108

Tkach VV, Świderski Z (1998) Differentiation and ultrastructure of the oncospheral envelopes in the hymenolepidid cestode Staphylocystoides stefanskii (Zarnowski, 1954). Acta Parasitol 43: 222-231 